CASA, Vol.8 n.2, dezembro de 2010

$\underset{C A S A}{C}$

Cadernos de Semiótica Aplicada

Vol. 8.n.2, dezembro de 2010

\title{
IGNACIO ASSIS SILVA: A FANTÁSTICA FÁBRICA DE CONEXÕES
}

\author{
IGNACIO ASSIS SILVA: \\ THE FANTASTIC CONNECTION FACTORY
}

\author{
Ana Cristina Fricke MATTE \\ UFMG - Universidade Federal de Minas Gerais
}

Daniervelin Renata Marques PEREIRA

USP - Universidade de São Paulo

\begin{abstract}
RESUMO: Este texto apresenta algumas reflexões a partir do pensamento de Ignacio Assis Silva sobre alguns pontos polêmicos da semiótica, como a natureza discreta ou contínua da semiose. Privilegiamos, então, a educação a distância como fenômeno a ser analisado em suas proximidades e deslocamentos em relação à prática pedagógica presencial de um ponto de vista tensivo.
\end{abstract}

PALAVRAS-CHAVE: Quadrado Semiótico; Tensividade; Educação a Distância.

ABSTRACT: This paper presents some reflections from the thought of Ignacio Assis Silva on some controversial points of semiotics, as discrete or continuous nature of semiosis. Then, we privilege the distance education as a phenomenon to be analyzed in its proximity and displacement in relation to the face-to-face interaction of a tensive point of view.

KEYWORDS: Semiotic Square; Tensivity; Distance Education.

\section{Introdução}

A semiótica greimasiana é uma ciência: ciência do sentido. Fazer ciência ou tomar ciência? Em que universo exato ou humano reside uma ciência do sentido? Dados de linguagem ou dados do mundo? Sem estar diretamente respondendo a essas questões, o professor Ignacio Assis Silva, por muitos considerado o maior semioticista do Brasil, contavanos histórias de paixões e apaixonados, de tensões e significações, de cursos e intercursos linguageiros, sempre buscando mostrar a beleza e a eficiência dessa ciência dinâmica, sempre em construção, no trato com os assuntos da linguagem humana. A despeito de qualquer crítica a uma eventual natureza fechada, a-histórica e acontextual da semiótica greimasiana, por seu cunho estruturalista, já na década de 70, Ignacio nos presenteava com discussões sobre a dinâmica da produção do sentido, mostrando, no seio da teoria, as sementes para a discussão do contínuo no mundo então aparentemente só descontínuo do estruturalismo. (cf. GREIMAS e FONTANILLE, 1993). 
Neste artigo, vamos apresentar reflexões a respeito da natureza discreta ou contínua da semiose, procurando mostrar a aplicação do pensamento ignaciano nos objetos por nós trabalhados.

O modo de fazer ciência muda conforme o objeto, e o que pretendemos discutir aqui é a pertinência do uso de uma teoria única - a semiótica - para abordar tantos e tão variados objetos, como é comum e aceitável no seio dessa teoria. Focalizaremos essencialmente um objeto: a produção de sentido no ambiente digital de comunicação na internet, em especial na EaD (Educação a Distância).

\section{Entre números inteiros e números reais}

O quadrado semiótico é assunto polêmico: falar em semiótica greimasiana e não falar do quadrado quase chega a heresia. Não que a semiótica restrinja-se a ele - muito pelo contrário, a semiótica, pode-se dizer, "superou" o quadrado semiótico há muito tempo. Essa por assim dizer "superação" veio na forma de exploração do quadrado em níveis e mesmo lógicas totalmente diferentes da original. Pode-se usar o quadrado para analisar temas e figuras, paixões, sujeitos, tipos de manipulação e até relacionando não um, mas dois campos semânticos, como é o caso do quadrado da veridicção. Se, por um lado, esse uso extrapolado do quadrado semiótico colocou-o em xeque em muitos contextos, por outro lado, também permitiu que a teoria explorasse a ideia original do quadrado sem deturpar sua operacionalidade.

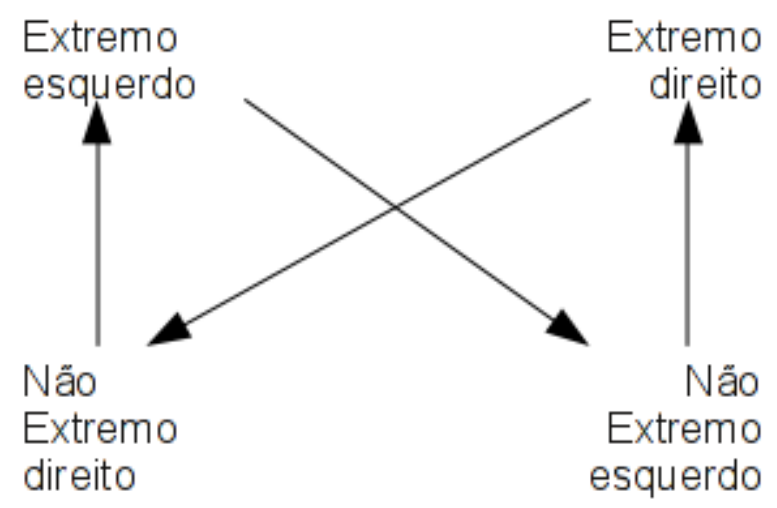

Ilustração 1: Quadrado semiótico: extremos de um campo semântico

E que operacionalidade é essa? O quadrado parece um esquema muito banal se visto estaticamente (Ilustração 1). Num campo semântico qualquer, temos uma oposição entre dois extremos contrários. O quadrado permite valorizar estágios intermediários que, numa dicotomia, são praticamente anulados: existem, mas sofrem um "arredondamento", no sentido matemático do termo.

Esse "arredondamento" é bastante compreensível: a linguagem discretiza o mundo contínuo, pois é impossível ter sentido no amorfo. Identidades e diferenças são criadas a partir de um mundo contínuo como efeito de uma decisão arbitrária sobre um ponto de estabilidade. A rigor, sequer dicotomias existem, pois os extremos são tão somente pontos 
arbitrários no mundo contínuo. Um exemplo clássico é a oposição quente/frio, a qual, à primeira vista, parece indubitavelmente constituir uma dicotomia, mas sempre podemos encontrar um ponto mais frio ou mais quente estendendo essa linha. A própria língua provê termos para isso: gelado e fervente estão, respectivamente, além e aquém dos pretensos extremos dessa dicotomia. Com o quadrado e suas posições "complexo" e "neutro" - que instauram a invasão do participativo sobre o exclusivo (SILVA, 1995, p. 65) -, podemos entender melhor por que essa dicotomia é, no mínimo, forçada em alguns casos (Ilustração 2). O quadrado delimita o campo semântico como relações entre esses "pontos" arbitrariamente alocados em posições opostas: se o quente é o extremo, por exemplo extremo esquerdo, e o frio é o extremo direito, o "gelado" - ou fervente - não tem lugar nesse campo semântico, já que, além ou aquém dos extremos, temos um termo complexo, definido por " $\mathrm{e}$ " (quente $e$ frio, no caso), o que definitivamente não define "gelado" - ou fervente -, mas é a posição na qual deveríamos dispor "gelado" - ou fervente - nesse campo semântico.

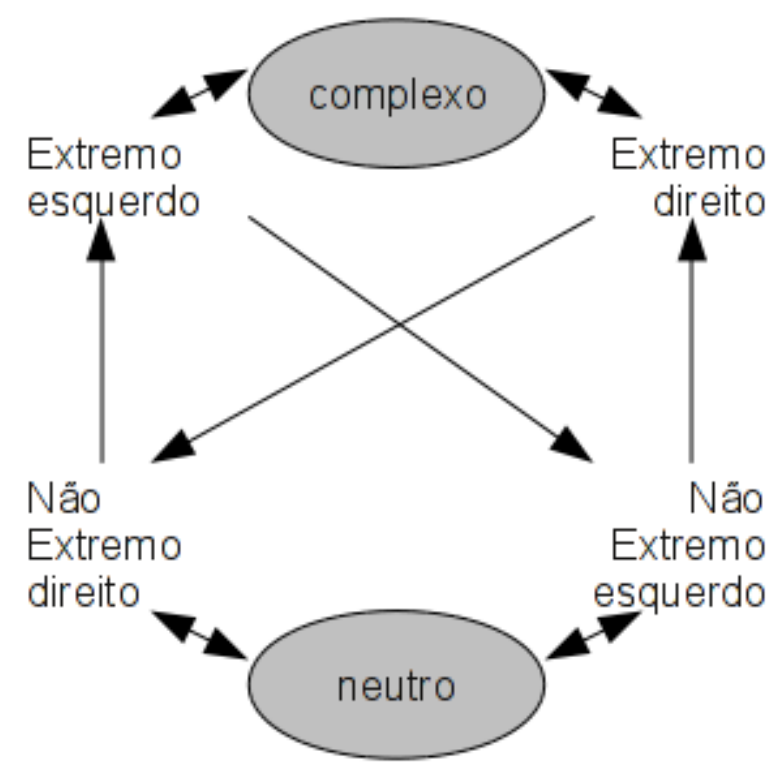

Ilustração 2: Enquanto o complexo concentra em si os contrários, o neutro concentra os subcontrários

Ajustar os extremos para essas novas posições pode resolver provisoriamente o problema, mas não é garantia de solução definitiva, já que a língua e principalmente a semiótica do mundo natural podem sempre apresentar uma gradação a mais na escala: congelado? Tórrido?

Tecnicamente, poderíamos dizer que esse universo semântico está relacionado à movimentação das moléculas: quanto mais movimentadas, mais quente, e vice-versa. Poderíamos argumentar que há um limite para o gelado, já que a falta de movimento no mundo real não pode ser menos que zero, mas tudo depende de escala: balançar a mão, tremer a mão e sustentar a mão imóvel só seriam um decrescendo em direção à imobilidade absoluta se a mão morresse no fim do caminho.

Além do mais, um leve tremor não é uma tremedeira... Nem um balanço frenético é um balanço leve. Quanto mais léxico for estudado para a colocação de termos contrários e subcontrários no quadrado, mais "redondo" ele fica, já que aumenta muito o número de cantos. $\mathrm{E}$ isso sem desconsiderar a natureza descontínua da linguagem, pois um 
leve tremor pode ser irregular, variando do imperceptível para o notável, por exemplo, sem deixar de ser um leve tremor (cf. GREIMAS, 2002).

As ciências exatas ensinam que os números inteiros e os números reais não se misturam. Enquanto os inteiros partem do princípio de unidade, os reais baseiam-se na premissa da totalidade. Números inteiros são $\{1,2,3,4,5 \ldots\}$. Entre um e outro, existe somente a diferença. Nos reais, entre um e outro existem sempre outros: $\{\ldots 1,1,1,1,11$, $1,111,1,2,1,3,1,55,1,999,1,999999,2 \ldots\}$.

O termo "leve tremor" é uma unidade: não se mistura com a quantificação inevitavelmente dinâmica e contínua do movimento físico da mão no espaço. Enquanto a unidade é indivisível, a totalidade é eternamente divisível. O quadrado, visto como relação entre dicotomias, pertence ao conjunto dos inteiros, mas o grande trunfo do quadrado foi trazer a divisão para aquilo que era relação entre unidades, autorizando-nos a pensar que haveria, sim, uma ponte entre unidade e totalidade. A totalidade em si é o conjunto fechado das coisas, portanto sua divisibilidade é mais potencial do que real: no momento em que passamos a destacar suas partes - e note que destacar aqui também tem o sentido de separar a totalidade se desfaz, o todo passa a ser tudo.

No entanto não se pode perder de vista que todos esses termos - unidade, totalidade, tudo, todo ${ }^{1}$ - são termos da linguagem que designam discrições dentro do contínuo do sentido. Como fazer, então, para entender a relação entre o efeito quantitativo do tremor das mãos concreto para o tremor das mãos enunciado? Seria interessante pensar essa oposição como uma relação entre valências constituindo um sistema tensivo.

forma mais abstrata:

Estes quatro termos - unidade, totalidade, tudo, todo - podem ser estudados de

$>$ Unidades são pedaços mínimos e predeterminados de alguma coisa. Podem ser consideradas como os fatores decisivos para se determinar um limite de divisibilidade. Por ser mínima e predeterminada, a unidade possui extensidade e intensidade mínimas.

$>$ Total é a soma das unidades, portanto dada pelo acréscimo tanto em termos de extensidade quanto em termos de intensidade. As unidades e o total são, portanto, elementos de um mesmo campo semântico e compõe um modelo tensivo converso.

$>$ O todo, uma unidade global, é uma opção ao total, cuja variação no campo semântico modifica apenas a concepção da divisibilidade: deixamos de ver a máxima apreensão como uma soma das unidades para ver a máxima apreensão como uma mudança de escala (de uma unidade pequena a uma unidade grande).

O tudo, por sua vez, tende ao infinito, o que nos traz um quadro tensivo de apreensão máxima e foco mínimo. Trata-se de um sistema, portanto, inverso, de modo que qualquer elemento colocado no extremo oposto ao tudo teria intensidade máxima e extensidade mínima. Esse elemento não aparece nos nossos quatro termos. Falar em oposição ao tudo traz à cena o nada, que pode

\footnotetext{
${ }^{1}$ Interessante lembrar que Greimas (1986), num ensaio de descrição semântica com base num estudo de Brøndal sobre os indefinidos Totus e Omnis, argumenta que tal organização traz à tona a visão humana de totalidade e universalidade. O primeiro (todo), termo integral, sublinha a noção de solidariedade de um grupo social e também de absorção dos indivíduos isolados numa massa indivisível, e o segundo (tudo), termo numérico, pode ser tomado como a reunião de indivíduos num grupo, em que as partes são reconhecidas.
} 
CASA, Vol.8 n.2, dezembro de 2010

ser concebido como o limiar infinitesimal de intensidade máxima e extensidade mínima.

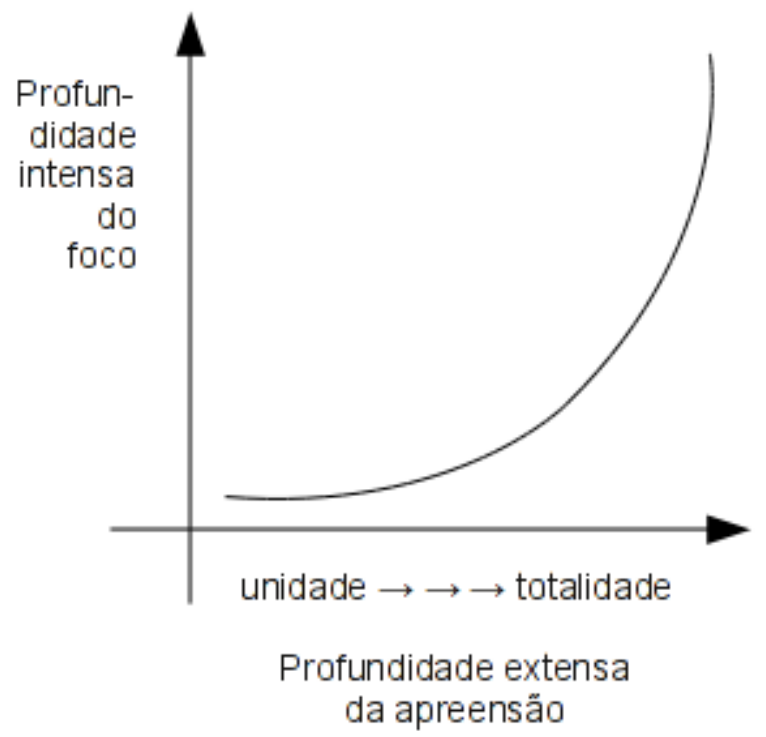

Ilustração 3: Curva tensiva da relação entre o foco e a apreensão para o campo semântico unidade versus totalidade

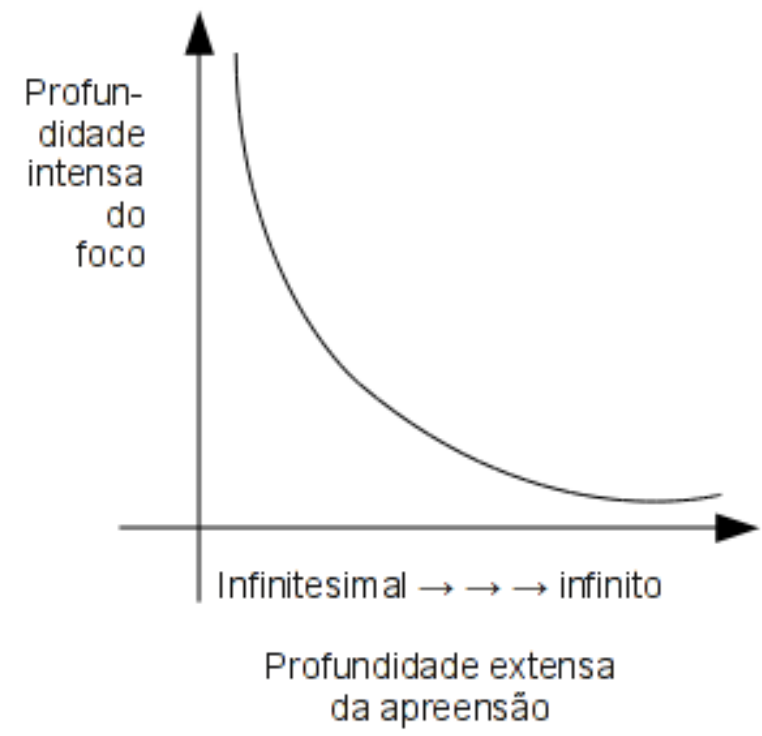

Ilustração 4: Curva tensiva da relação entre o foco e a apreensão para o campo semântico infinitesimal versus infinito (nada versus tudo)

O universo dos inteiros é caracterizado por uma divisão inabalável, por um arredondamento inevitável do mundo contínuo. Se minha régua só marca centímetros, uma moeda de cinco centavos terá o diâmetro de 2 centímetros. Se eu tiver também milímetros, direi que esse diâmetro mede 22 milímetros ou 2,2 centímetros. Se minha régua, além disso, mostra a metade dos milímetros, posso dizer que a medida é de 2,15 centímetros. 
Esqueçamos a matemática um pouco: é possível, com base nesse exemplo, entender que uma medida é sempre uma aproximação, um arredondamento e, portanto, não menos descontínua do que o universo dos inteiros, mesmo quando falamos em milímetros? É uma propriedade da linguagem essa de discretizar o mundo percebido, e é por meio dessa linguagem discretizante que conseguimos determinar categorias, oposições, congruências e discrepâncias. Entender o mundo é destacar partes de uma totalidade, é fruto de um processo de análise. No entanto a linguagem não despreza o contínuo: todo sujeito sabe que faz aproximações quando fala de um evento qualquer e só consegue comunicar-se com outro sujeito porque sabe que aproximações não são medidas exatas - e que medidas exatas nem existem. É um saber coletivo que é muitas vezes negado para a defesa de posturas pseudocientíficas, por isso todo cuidado é pouco.

Uma pessoa pode decidir que a mesma moeda de cinco centavos mede dois centímetros segundo a sua régua que só mostra centímetros; outra pode, com a mesma régua, decidir que essa moeda mede 2,5 centímetros, já que é maior que 2 e menor que 3 . Haverá quem diga que a medida é 2,3 centímetros; outro vai ler 2,2 na régua. E todos estão certos, pois todos estão errados: não existe medida exata, ninguém pode afirmar com exatidão, mesmo com um instrumento de alta precisão (bem diferente dessa régua), qual o diâmetro da moeda. Basta que se construa um instrumento mais preciso, e a medida anterior mostra-se nada mais que um arredondamento, independente de quantas casas alcançou depois da vírgula.

Não é à toa que os números reais são chamados assim: o mundo real não tem limites evidentes, o mundo real é amorfo, nós é que buscamos, nele, identidades e diferenças no processo de semiotização do mundo natural.

Para tentar fazer um modelo tensivo que explique a formatação descontínua do mundo contínuo pela linguagem, é preciso refletir sobre a natureza do conjunto dos números reais e a natureza do conjunto dos números inteiros. A unidade que diferencia um número inteiro qualquer de seu subsequente possui sempre o mesmo tamanho. Já a unidade no número real nem mesmo pode ser compreendida como tal, pois é sempre dinâmica, dependendo da escala de aproximação: quanto maior o foco, menor a unidade.

Podemos abordar essa questão do ponto de vista da percepção, já que a linguagem nada mais é do que o filtro dos sentidos para a compreensão do mundo. Uma profundidade intensa do sensível, ganhando luzes de temporalidade, compõe o campo tensivo da percepção com uma profundidade extensa da apreensão, na arena da espacialidade (Cf. MANCINI, 2008).

Os números inteiros são percebidos como unidades e totalidades: o mínimo foco corresponde à mínima apreensão, já que os números inteiros ganham força na soma, na criação de totalidades. De acordo com Fontanille e Zilberberg (2001, p. 130), apreender é "fazer coincidir a extensão de um domínio fechado com o campo em que se exerce a intensidade ótima da percepção", enquanto focalizar é "selecionar, numa extensão aberta, a zona em que se exercerá a percepção mais intensa; é renunciar à extensão e ao número de objetos, em prol da saliência perceptiva de alguns, ou de um único". Assim, pode-se dizer que o modelo tensivo dos números inteiros é converso: quanto maior a apreensão, maior o foco. Isso porque a ideia é que se somam partes para se alcançar um conjunto pleno, ou seja, a "intensidade ótima da percepção" é dada pela extensidade, pela apreensão. Podemos ainda considerar que os "inteiros" se relacionam a valores de absoluto, associados às operações de triagem, e os "reais", a valores de universo, associados à mistura.

Os números reais, por não serem determinados por unidades de tamanho fixo, opõem o infinitesimal ao infinito. O infinitesimal é a divisibilidade extrema: a escala de 
aproximação é inversa à percepção desses detalhes, ou seja, quanto menor a escala, maior a especificidade (mais números após a vírgula). Em termos de percepção, o que temos é que a menor apreensão corresponde ao maior foco, ou seja, o infinitesimal é alcançado pela minimização espacial, enquanto a maior apreensão, que tende ao infinito, dilui o foco. Conclui-se que o modelo tensivo dos números reais é de tipo inverso.

Portanto a intensidade máxima dos reais está na apreensão mínima, enquanto a intensidade máxima dos inteiros está na extensidade máxima, o que comprova, semioticamente, a premissa matemática da incompatibilidade dos dois conjuntos de números Reais e Inteiros.

$\mathrm{Na}$ próxima parte, discutiremos alguns dados sobre ensino a distância, que serão, na última seção, analisados segundo esses dois modelos tensivos.

\section{Entre práticas - o caso da EaD}

As práticas de educação com uso de novas tecnologias são vistas atualmente como "em transição" (MORAN, 2002; PETERS, 2004), pela mistura entre elementos do presencial e do digital que se tornou usual entre os professores, em geral, já habituados à rotina das práticas presenciais. Com isso, fala-se em sobreposição de prática,s e o resultado, acreditamos, não é uma modalidade totalmente nova nem uma simples soma de elementos dos dois contextos. É verdade que o objetivo de fazer-saber é mantido tanto no presencial como no digital, bem como a euforização do conhecimento como valor essencial, e pensamos que não há transformações suficientes ainda para se identificar uma nova classe, mas reconhecemos aí um movimento de deslocamento. Procuramos, então, pensar nos limites.

Alguns traços distintivos do ensino-aprendizagem pelo ambiente digital nos

ajudam a pensar nisso. É bem comum que as atividades a distância apresentem, logo no início, um tutorial, ou seja, um passo a passo dos procedimentos necessários que o sujeito precisa colocar em prática para usar o ambiente e a forma de organização dessa atividade como um percurso programado. Esse tutorial traz sobretudo um conhecimento das formas de ocupação do espaço digital, principal diferença dessa prática. Já as regras para o modo de presença na sala de aula presencial, tidas como tradicionais, são adquiridas culturalmente e, em poucos anos, fazem parte dos hábitos sociais do indivíduo que passa pela escola. Outro traço são as formas de relação interpessoal. Presencialmente, os sujeitos se reúnem fisicamente e, no digital, essa relação é mediada pelas tecnologias em uso. Podemos, por outro lado, considerar efeitos de proximidade ou distanciamento, maior ou menor participação, mas teríamos sempre de partir de pontos de vista e percepções discursivizadas do sujeito que sente.

Por hora, buscamos compreender o movimento mais geral que faz nascer uma prática educativa em ambiente digital partindo do que se considera como práticas tradicionais ou convencionais, ou seja, na relação que cria a diferença. Sabemos que, à medida que se muda o sistema de educação, tende-se para a mudança dos papéis ocupados pelos sujeitos e objetos. No caso da EaD (Educação a Distância), se os sujeitos precisam explicar como funciona a prática, é porque apenas os conhecimentos culturais do que seja escola não são suficientes. Se o digital suprime determinados tipos de performance do sujeito, é preciso encontrar novas formas de interagir. Percebemos, pois, certas coerções do meio que exigem adaptações, ajustes, para que a aquisição do objeto semelhante não seja impedida. Estariam, então, essas transformações apenas relacionadas à tecnologia? De acordo com Moore e Kearsley (2007, p. 20), "a tendência é agregar novas tecnologias de comunicação ao sistema 
existente e, então, deixar os outros subsistemas pouco alterados", o que se faz por insegurança em relação à mudança dos subsistemas organizacionais e pedagógicos.

Ao tomar esse fenômeno como sistema semiótico, poderíamos localizá-lo sob diferentes categorias elementares: escrita versus oral, tradicional versus inovador, presencial versus digital, entre outras. Como vimos anteriormente, confiar apenas nos extremos e anular, assim, os pontos intermediários não é produtivo nessa reflexão. Além disso, apenas poderíamos indicar tendências para cada termo e, muitas vezes, até sobreposição das modalidades num determinado ponto. Fato é que encontrar oposição abrangente para a diferença nas modalidades desconsiderando as variações é impossível, se se quer ser científico, e isso confirma, talvez, essa posição transitiva que já mencionamos; não é possível pensar de forma mais geral numa modalidade sem ver a outra.

Tomemos alguns enunciados da mídia que, em última instância, trazem à luz representações ideológicas da sociedade (FIORIN, 2006). Eles também parecem refletir cautela no anúncio de um novo paradigma de ensino-aprendizagem; mas, ao contrário, um diálogo entre objetos tradicionalmente usados na educação e outros que sinalizam a inovação:

[...] Um dia na rotina dessa pré-escola mostra como a tecnologia foi incorporada de forma natural ao processo de ensino e aprendizagem, de modo que hoje o computador tem status de material básico de ensino - o mesmo pode ser observado em outras unidades da rede municipal. A naturalidade dos pequenos diante das máquinas comprova essa afirmação. "Tô escrevendo um carta ${ }^{2}$, diz Júlia, enquanto tenta digitar seu nome. Enquanto ela tecla, outros brincam ou desenham. "Alguns pais ficaram aflitos achando que cadernos, livros, canetas e lápis iam ser abolidos. Mas só acrescentamos uma nova ferramenta, que também serve para ensinar", diz Lúcia Helena Borges, chefe da Divisão Pedagógica da Secretaria Municipal de Educação. [...] (PIRES, 2010).

[...] 'As salas têm sempre as duas lousas, porque somos da geração da transição, com giz e mouse, que não brigam”, diz a diretora pedagógica Débora Vaz. [...] Toda a tecnologia disponível, no entanto, não assegura por si só uma revolução educacional. [...] O desafio agora é garantir o bom uso da tecnologia. "O risco é repetir o velho com a ferramenta nova', diz Nilbo Nogueira, doutor em educação pela Pontifícia Universidade Católica de São Paulo (PUC-SP) [...]. (MAMBRINI, 2010).

Por que fazer pós-graduação online na Cruzeiro do Sul? Porque eu posso ter todo o conteúdo de uma universidade nota máxima no MEC onde e quando quiser, na tela do meu computador. (propaganda da Universidade Cruzeiro do Sul na Folha de São Paulo, 2010, p. 2).

Por trás da variedade presente nos trechos, encontramos o computador como objeto central entre o que é tomado como velho versus novo, comum versus diferente, rígido versus flexível. Temos aí posições que vão desde a incorporação da máquina no exercício da prática pedagógica até a possibilidade de reproduzir todos os saberes de uma instituição em sua tela. Ainda é possível, pelo segundo excerto, a convivência harmônica desde que feitas as adequações.

\footnotetext{
${ }^{2}$ Os trechos estão aqui registrados como no original.
} 
O que consideramos relevante nesses enunciados a que tivemos acesso e que são reunidos pela proximidade do tema é o diálogo entre as formas de ensino-aprendizagem o qual torna as fronteiras entre as práticas extremamente difusas, quase inexistentes às vezes. Entretanto é possível demarcar aí uma passagem gradual. De um extremo a outro, também baseados em nossa experiência, podemos ter as seguintes possibilidades ${ }^{3}$, coexistentes ou como processo:

\begin{tabular}{|c|c|c|c|}
\hline $\begin{array}{c}\text { Presencial } \\
\text { convencional }\end{array}$ & $\begin{array}{l}\text { Presencial } \\
\text { com novas } \\
\text { tecnologias }\end{array}$ & $\begin{array}{l}\text { Digital } \\
\text { com técnicas } \\
\text { convencionais }\end{array}$ & $\begin{array}{l}\text { Digital } \\
\text { inovador }\end{array}$ \\
\hline $\begin{array}{l}\text { Algumas situações: } \\
\text { 1) uso de lousa e giz; } \\
\text { 2) alunos em } \\
\text { carteiras e usando } \\
\text { material impresso; } \\
\text { 3) pouca } \\
\text { participação dos } \\
\text { alunos; } \\
\text { 4) aulas expositivas; } \\
\text { 5) avaliação por } \\
\text { provas escritas. }\end{array}$ & $\begin{array}{l}\text { Algumas situações: } \\
\text { 1) uso de laboratórios } \\
\text { com computadores, } \\
\text { data-show e outras } \\
\text { tecnologias. Espaço } \\
\text { físico comum; } \\
\text { 2) maior liberdade } \\
\text { dos alunos para } \\
\text { administrar as tarefas } \\
\text { no computador. }\end{array}$ & $\begin{array}{l}\text { Algumas situações: } \\
\text { 1) uso de plataformas } \\
\text { digitais com } \\
\text { utilização de apostilas } \\
\text { e outros textos } \\
\text { impressos; } \\
\text { 2) transmissão ao } \\
\text { vivo de aulas - } \\
\text { transposição de } \\
\text { formas de } \\
\text { aprendizagem } \\
\text { tradicionais para o } \\
\text { ambiente online; }\end{array}$ & $\begin{array}{l}\text { Algumas situações: } \\
\text { 1) métodos, materiais, } \\
\text { ferramentas típicos do } \\
\text { digital; } \\
\text { 2) os alunos, mesmo } \\
\text { que conheçam as } \\
\text { ferramentas usadas, } \\
\text { precisam se adaptar à } \\
\text { nova abordagem; } \\
\text { 3) há uma relativa } \\
\text { liberdade na } \\
\text { participação dos } \\
\text { alunos (em chat, por } \\
\text { exemplo); } \\
\text { 4) a própria } \\
\text { organização da aula é } \\
\text { colocada sob } \\
\text { discussão. }\end{array}$ \\
\hline
\end{tabular}

Podemos ainda, diminuindo o tamanho das unidades da escala que vai de um extremo a outro, pensar em algumas posições intermediárias:

- Aula em sala física, mas com desestabilização das posições entre os sujeitos. A interação é eficiente dentro das possibilidades materiais.

- Ambiente inovador, mas incompatível com as relações de autoridade do professor e submissão do aluno.

Interessante notar que, para Peters (2004, p. 153), esse estado inovador estaria longe dos conceitos que temos e que podem estar representados no quadro citado. Para ele, o que pensamos hoje está ainda muito vinculado a nossas experiências de escola, e uma nova perspectiva estaria ligada a novos caminhos, a "um paradigma pós-moderno de

\footnotetext{
${ }^{3}$ Ver mais detalhes em MATTE, Ana Cristina Fricke. Análise da sala de aula no tempo da EaD. Revista Tecnologias na Educação. 2009. Disponível em: http://tecnologiasnaeducacao.pro.br/revista/a1n1/pal3.pdf. Acesso em: 15 nov. 2010.
} 
aprendizagem" (p. 62). Esse paradigma estaria relacionado a um ajustamento completo de tecnologia, método, conteúdo, público e espaço pelo menos, fatores intimamente ligados.

Fontanille e Zilberberg (2001, 146-147) sugerem que no lugar de "estado", pensemos em "fases tensivas", em que, no processo de conversão, podemos ter um limiar ou um limite. Nesse caso, no lugar de um limiar entre uma prática que evolui de digital, com técnicas convencionais, para outra forma, a inovadora, podemos pensar na primeira fase como um limite intencional ou não.

Essa noção de movimento e parada fica marcada nos textos citados e nessas representações das fases. Ao lado da segurança da estabilidade, garantida pelo convívio de diferentes ferramentas, vislumbra-se uma "revolução educacional" ainda não alcançada. Nesse caso, a imagem criada é de sujeito em falta, que precisa se ajustar à época, sair do parecer e chegar ao ser. Outros valores, entretanto, influenciam a aceitação desse movimento de saída do dado em direção a novas experiências, é a manipulação pelo reconhecimento institucional do conteúdo agregado à sua mobilidade compatível com o sujeito dinâmico que quer ser bem-sucedido.

Também identificamos como subentendido a complexa relação do sujeito com o "novo". Como explicam Fontanille e Zilberberg, após um curto momento de impacto, "o sujeito se esforça, a exemplo de qualquer vivente, por tornar esse nicho [espaço tensivo] habitável, isto é, por ajustar e regular as tensões, organizando as morfologias que o condicionam" (2001, p. 128). É nessa tentativa de regulação que encontramos professores e alunos muitas vezes, ao se defrontarem com o ambiente digital em busca de uma prática nova, mas que seja apreensível pelos sujeitos de tal forma que o objeto não seja obstruído pelo processo de sua aquisição. Daí, entendemos melhor a necessidade dessa "transição" gradual, própria do ser que está entre a identidade e a alteridade.

Sobre as tensões entre tradição e inovação, Fontanille (2008, p. 9-10) afirma que, numa dimensão macrossemiótica, elas advêm e se resolvem não em práticas particulares, mas no espaço e no tempo de uma cultura. É, portanto, a totalidade das práticas agregadas de valores míticos, históricos, literários etc. que explica uma tradição como um todo coerente. Já a inovação propõe uma nova organização de valores e figuras e suporta a reunião de elementos antes apartados, as incoerências advindas da confrontação de opções alternativas. Por meio dessa diferenciação, podemos ver que a distinção que caracteriza a inovação aqui seria, de acordo com a análise dos textos, uma nova prática que vai além da tecnologia, associando, talvez, elementos da própria prática presencial de uma forma inusitada.

Entretanto está claro para nós que a inserção das tecnologias relacionadas à transmutação dos gêneros mais primários de comunicação em outros, como chat e fórum, já faz parte de uma nova prática, com códigos e regras próprias. Podemos ver a educação a distância como um processo de acumulação de elementos no percurso que se faz desde as práticas convencionais, mas que não significa apenas soma. Essa prática, no ir e vir do ciberespaço para a sala de aula tradicional, acaba instaurando sua própria linguagem e propõe aos sujeitos outros percursos em busca de objetos historicamente valorizados e novas transformações possibilitadas nesse caminho. Trata-se, na verdade, de um processo de ressignificação da interação estabelecida entre atores no contexto pedagógico em que o próprio sujeito, ao buscar a transformação do meio, vê-se gradualmente contagiado pela mudança. 


\section{Unitário e totalidade versus infinitesimal e infinito}

A oposição entre presencial e online, no campo da educação, traz diferenças importantes para a discussão do processo ensino-aprendizagem. Tomemos esses dois extremos para pensar essa oposição:

espaço:

$>$ presencial: a presença na sala de aula é determinada no tempo e no espaço. Não estar na aula em determinado horário corresponde a uma ausência necessária e consequente perda de conteúdo.

$>$ online: estar presente deixa de basear-se numa dicotomia e passa a figurar como uma dinâmica de participação ou não participação, com o limite temporal estendido.

conhecimento:

$>$ presencial: a definição do conhecimento válido é estática. O conteúdo é predeterminado, e o professor garante que os alunos recebam esse conteúdo e depois cobra a sua compreensão.

$>$ online: o conhecimento ganha uma definição extensa e dinâmica. O que deve ser aprendido é mais do que o conteúdo preestabelecido; aprender a aprender torna-se imperativo, assim como valores como autonomia e colaboratividade, de modo que o professor deixa de ser o único detentor do saber para ser um parceiro na construção de um conhecimento. Seu papel só não fica mais diluído porque ele é o responsável por garantir que o conteúdo predeterminado esteja presente no conhecimento adquirido mesmo que seja de forma questionadora.

complexidade:

> presencial: como se fixa no conteúdo preestabelecido, a educação presencial busca manter uma linha de complexidade crescente na apresentação desse conteúdo, ou seja, do tido como mais simples para o tido como mais complexo.

$>$ online: a construção do conhecimento parte da complexidade do mundo real para uma organização linguageira, ou seja, o complexo é admitido logo no início do processo. Na busca por esclarecimento, definições e abordagens podem ser consideradas simplificadas, se notarmos que criam versões minimamente estáveis de um mundo dinâmico e, portanto, instável.

Poderíamos buscar muitas outras facetas dessa oposição, mas essas três são suficientes para nossa análise.

O ensino é uma instância que relaciona apreensão e foco, portanto cabe nos mesmos modelos da percepção acima discutidos.

O ensino presencial modelo parte do pressuposto que o conhecimento é categórico, discreto, passível de uma complexificação linear que não nega a discretização. 
Assim podemos assumir que o ensino presencial possui o inteligível como fonte e como meta, num quadro converso em que o foco aumenta com a percepção. Valoriza-se, deste modo, um saber cada vez mais especializado como parte de uma totalidade dividida em unidades de tamanho predeterminado. Essa modalidade de ensino, portanto, do início ao fim de um processo em busca da totalidade do conhecimento, segue a lógica dos números inteiros, em que a soma das unidades é a fórmula para constituir a totalidade.

O ensino a distância, em especial o online, parte do mundo natural, o mundo contínuo, dinâmico e, por isso mesmo, complexo, em busca das recorrências que permitam estabelecer possíveis unidades cada vez menores, do âmbito do infinitesimal. A busca por essas unidades implica a assunção de que o conhecimento pela linguagem é sempre um recorte, uma discretização: portanto o ensino online é bem-sucedido quando consegue simular o salto do conjunto dos números reais para o conjunto dos números naturais.

Assim o que acontece nesse ensino online modelo é a possibilidade de que todo aprendizado permita a reconstrução do conhecimento humano, pois admite que o homem é um ser biológico, dinâmico, contínuo e instável, ao mesmo tempo em que admite que o conhecimento, no mundo da linguagem, é dado pelo discreto, estável e, desse modo, estático.

É sob essa perspectiva que o ensino online modelo é mais flexível e abrangente. No entanto, como vimos no quadro de possibilidades de realização da prática educativa, o modelo é hipotético, existem infinitos pontos entre o modelo presencial e o online e, portanto, o conhecimento adquirido em cada tipo assim determinado traduz de diferentes formas a relação entre uma percepção discreta (números inteiros) ou contínua (números reais) do mundo.

O que chamamos de "presencial" pode estar determinado exclusivamente pela questão do espaço/tempo: o uso de tecnologias e metodologias pode derrubar barreiras em relação à definição do conhecimento válido, ao mesmo tempo em que a utilização da tecnologia como vitrine de uma metodologia tradicional produz o efeito contrário, impedindo o salto entre o contínuo e o discreto, simplesmente por ignorar completamente o primeiro. Podemos pensar que esse movimento de surgimento e mudança da modalidade de educação online traz em si elementos do presencial em transgressão, porque o próprio sistema carrega disposições para "o movimento desequilibrador, movimento a partir do qual se instaura sua metamorfose" (SILVA, 1995, p. 64). Nesse sentido, Silva fala de um ponto de vista metacrônico, "meta, 'trans' + chronos, 'tempo', transtempo, transversão, transgressão" (p. 64), que parece se aproximar do fenômeno que envolve os sujeitos que se inserem nesse deslocamento entre as práticas educativas.

A compreensão da relação desses modelos tensivos com a prática do ensinoaprendizagem é importante no sentido de possibilitar reflexões sociais (qual o papel da escola?), morais (qual o lugar do conflito e da indefinição nas relações?), humanas (qual o papel do indivíduo no mundo?) e científicas (que tipo de conhecimento é válido para as ciências?), dentre outras.

Todas essas reflexões vêm ao encontro do movimento de Ignacio Assis Silva na construção do conhecimento: conhecimento não é simples resultado de soma, é resultado de idas e vindas, de aceitação e questionamento, da carne do sentido e do sentido da carne. Esperamos ter recriado aqui, com nossa discussão, uma pequena amostra da fábrica de conexões que herdamos desse semioticista brilhante. 
CASA, Vol.8 n.2, dezembro de 2010

\section{Referências bibliográficas}

FIORIN, José Luiz. Linguagem e ideologia. São Paulo: Ática, 2006.

FOLHA DE SÃO PAULO. Propaganda da Universidade Cruzeiro do Sul. In: Folha de São Paulo especial. Domingo, 14 de março de 2010, p. 1-12.

FONTANILLE, Jacques e ZILBERBERG, Claude. Tensão e significação. Trad.: Ivã Lopes, Luiz Tatit e Waldir Beividas. São Paulo: Discurso Editorial: Humanitas/FFLCH-USP, 2001.

FONTANILLE, Jacques. Pratiques et cultures: tradition, innovation et bricolage. In: Sémiotique des pratiques. Paris: PUF, 2008.

GREIMAS, Algirdas Julien. Comment définir les indéfinis? Actes sémiotiques - Documents. VIII, 72, 1986, p. 3-18.

GREIMAS, Algirdas Julien e FONTANILLE, Jacques. Semiótica das paixões. São Paulo, Ática, 1993.

Da imperfeição. São Paulo, Hacker Editores, 2002.

MAMBRINI, Verônica. Tecnologia na sala de aula. In: Revista Isto É. Disponível em: $<\mathrm{http} / / / \mathrm{www}$.istoe.com.br/reportagens/71458_TECNOLOGIA+NA+SALA+DE+AULA?path Imagens $=\&$ path $=\&$ actualArea=internalPage $>$. Acesso em 07 de novembro de 2010.

MANCINI, Renata Ciampone. Ausência em Michelangelo Antonioni, de Caetano Veloso. Revista Encontros de Vista (UFRPE), v. 1, p. 1-13, 2008.

MOORE, Michael e KEARSLEY, Greg. Educação a distância: uma visão integrada. Trad. Roberto Galman. São Paulo: Thomson Learning, 2007.

MORAN, José Manuel. O que é educação a distância. In: Informe CEAD - Centro de Educação a Distância. SENAI, Rio de Janeiro, ano 1, n. 5, out-dezembro de 1994, p. 1-3. Atualizado em 2002. Disponível em <http://www.eca.usp.br/prof/moran/dist.htm>. Acesso em 29 de junho de 2010.

PETERS, Otto. A educação a distância em transição: tendências e desafios. Trad. Leila Ferreira de Souza Mendes. São Leopoldo: Ed. Unisinos, 2004.

PIRES, Alaíde. Computadores na pré-escola. In: Nova escola. Edição 232, Maio 2010. Disponível em: <http://revistaescola.abril.com.br/educacao-infantil/4-a-6-anos/computadorespre-escola-556251.shtml>. Acesso em 07 de novembro de 2010.

SILVA, Ignacio Assis da. Brøndal, Hjemslev, Greimas. In: OLIVEIRA, Ana Claudia e LANDOWSKI, Eric (eds.) Do inteligível ao sensivel: em torno da obra de Algirdas Julien Greimas. São Paulo: EDUC, 1995, p. 55-68. 